\title{
Implicações da variação na alfabetização: a lateral palatal e seus correspondentes grafêmicos
}

\author{
Raquel Meister Ko. Freitag
}

Doutora em Linguística. Professora da

Universidade Federal de Sergipe. E-mail:

rkofreitag@uol.com.br

Resumo: A partir dos pressupostos da sociolinguística e da fonologia de usos, abordamos neste texto a realização da lateral palatal $[K] \mathrm{e}$ suas variantes $[l]$, [l] e [y] e os correspondentes grafêmicos "lh", "l" e "i" no universo de alunos do primeiro ciclo da educação básica. A metodologia adotada foi quantitativa. Os dados apontam para a correlação, mediada pela escola, entre o repertório de representações da oralidade e o repertório de representações da escrita.

Palavras-chave: Lateral palatal; Representação grafofonêmica; Variação; Sociolinguística.
Abstract: Based on Sociolinguistic and Phonology and use approaches, in this text the lateral aproximant $[K]$ and its variant $[l]$, $[j]]$ e $[y]$ and its graphemic variants "lh", "l" e "i" are analyzed in the $1^{\text {st }}$ cycle of basic education pupils. The quantitative methodology is adopted. The data point that there is a correlation, mediated by school, between the oral repertory of representations and the written repertory of representations.

Keywords: Lateral approximant palatal; Graphophonemic representations; Variation. Sociolinguistics. 

Vício na fala

Para dizerem milho dizem mio

Para melhor dizem mió

Para pior pió

Para telha dizem teia

Para telhado dizem teiado

E vão fazendo telhados.

(Oswald de Andrade)

\section{Introdução}

Se o processo de alfabetização se resumisse à conversão unívoca de fonemas a grafemas, o trabalho do professor seria muito mais simples. Ocorre que as normas ortográficas - norma aqui entendida como uma convenção - não obedecem ao input ao qual a criança está exposta, à sua variedade linguística. Tome-se, por exemplo, a realização fônica do dígrafo "lh", para o qual Cristófaro-Silva (2000, p. 64) descreve três possibilidades: lateral palatal ['paКa]; lateral alveolar palatalizada ['palia]; e iode ['paya] ${ }^{1}$. Trata-se de um fenômeno variável no português: em determinados contextos, por facilidade ou relaxamento de articulação (CAMARA Jr., 1972), o $[K]$ pode perder o traço palatal, passando a ser articulado como alveolar [1], como iode [y] ou sofrer apagamento, desaparecendo. A correlação grafofonêmica neste contexto não é unívoca, e a escolha de uma ou outra forma traz implicações sociolinguísticas, como bem afirma Brandão (2007, p. 91): “o cancelamento - como em [miv] por milho - e as variantes [1] e [y] - como em

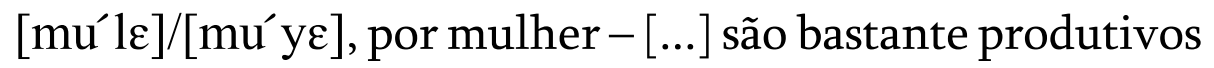
na fala de comunidades rurais ou de grupos com baixo ou nulo nível de escolaridade." Para esta autora,

o padrão não marcado socialmente incluiria, além da variante $[K]$, as variantes [1], quando seguida de $[\mathrm{i}]$ - fo[l]inha, por exemplo - e/ou [li], estas

1 Há que se mencionar ainda a realização lateral alveolar, prevista por Camara Jr (1972): ['pala]. 
últimas consideradas por Camara Jr. 'típicas da variedade relaxada' [...] O padrão marcado socialmente seria aquele em que, além das três ou de uma ou duas das referidas variantes, se encontram o cancelamento (como em ['miu]), a variante [y] e o [1] diante de vogais diferentes de [i] (como em [múl le]). (BRANDÃO, 2007, p. 97, grifos da autora).

$\mathrm{Na}$ variedade linguística sergipana, a realização variável da lateral palatal pode ser constatada, por exemplo, com dados do Atlas Linguístico de Sergipe II (CARDOSO, 2005). A carta 13 refere-se ao item lexical "joelho", da área semântica HOMEM. Vejamos a distribuição das variantes na figura 1.

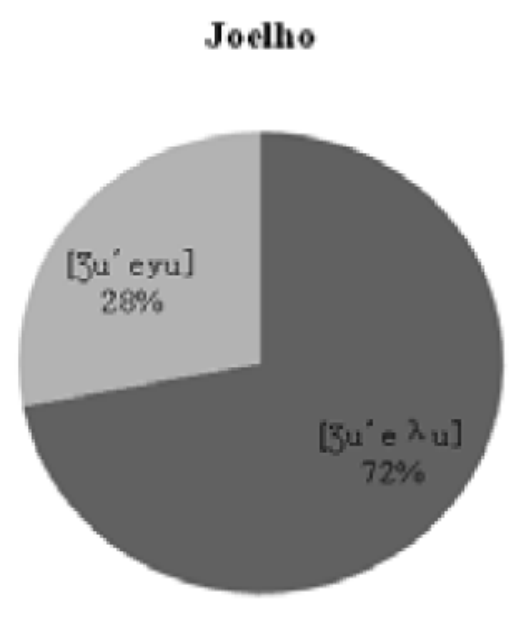

Figura 1: Distribuição das variantes da lateral palatal para o item lexical “joelho" do Atlas Linguístico de Sergipe II (CARDOSO, 2005, carta 13)

De acordo com a distinção de Brandão (2007) para a marcação social das variantes, com a oposição entre $[\Lambda]$ como forma não marcada socialmente e [y] como forma marcada, vemos um padrão de distribuição na fala em que há tendência ao predomínio da forma não marcada, com $72 \%$ das ocorrências. A partir deste input, como, então, a criança irá formular suas regras de representação grafofonêmica para o dígrafo "lh"? Podemos buscar uma 
resposta assumindo a premissa sociolinguística de que o sistema linguístico é regido por regras variáveis, que podem ser mais ou menos aplicadas, dependendo do ambiente linguístico e/ou social, o que define a natureza do sistema como probabilística e pressupõe o emprego de técnicas quantitativas para a observação das regularidades que o regem. Afinal, mudança é questão de frequência. (LABOV, 1994, p.25).

Assim, se a criança está exposta a um sistema em que coocorrem formas como $[K]$ e $[y]$ para o mesmo contexto, como ela firmará a representação fonêmica da lateral palatal? A fonologia de usos (BYBEE, 2001) pode auxiliar na explicação. A proposta da fonologia de usos é explorar fenômenos que são tradicionalmente estudados pela fonologia, reavaliando as noções estruturais em termos de uso e substância. (BYBEE, 2001, p. 6). Para esta perspectiva, o uso da língua modela a forma e o conteúdo dos sistemas de sons. A frequência com que dada palavra ou sequência de palavras são usadas e a frequência com que certos padrões recorrem em uma língua afetam a natureza da representação mental e, em alguns casos, o corpo fonético das palavras. (BYBEE, 2001, p. 1).

O foco na estrutura precisa ser suplementado com uma perspectiva que inclua mais que apenas a estrutura; a substância e o uso da língua também devem ser considerados. Por substância, entende-se a forma fonética e a forma semântica e a correlação estabelecida entre estas duas formas via língua. $\mathrm{O}$ uso compreende não só o processamento da língua, mas os usos sociais e interacionais da língua (BYBEE, 2001, p. 2) e é nesse ponto que fazemos a correlação com a Sociolinguística, com a produtividade das variantes em dados contextos e a marcação social à qual as formas estão sujeitas. Como diz Cristófaro-Silva (2006, p. 28), “sons similares que caracterizam propriedades sociais da linguagem".

Em termos de organização mental, a fonologia de uso se assenta no papel da frequência: a frequência com que 
certas palavras, sintagmas ou padrões são utilizados tem impacto no sistema fonológico. (BYBEE, 2001, p. 2). Um modelo de língua baseado em uso pressupõe, então, que a experiência afeta a representação. Palavras e sintagmas que têm alta frequência têm representações mais fortes, no sentido de que são mais facilmente acessadas e menos propícias a sofrerem mudança por analogia. Já as palavras e sintagmas que têm baixa frequência são mais difíceis de serem acessadas e tornam-se mais difíceis de serem lembradas. Voltando ao caso de "joelho", na figura 1, um falante da variedade sergipana pode estar exposto a diferentes realizações da palavra (representações), como [3u'eKu], [3u' $e^{y} u$ ], [Zu'ey], [Zu' ey ${ }^{u}$ ] (cf. CARDOSO, 2005, carta 13). As representações são acumuladas no decorrer da vida, mas é no período da aquisição até a adolescência que as representações se consolidam no sistema linguístico do falante (CRISTÓFARO-SILVA, 2006, p. 35). É neste período também que o falante passa a ter contato com a normatização e convencionalização ortográfica da língua, por meio da alfabetização, e exposição à variedade culta da língua, processos que ocorrem no espaço escolar. Considerando a atuação desses dois processos, como fica a organização do sistema linguístico do falante no que diz respeito às regras de conversão grafofonêmica em uma variedade linguística em que a lateral palatal tem mais de uma realização, sendo uma delas marcada socialmente? Se o falante está exposto a uma variedade linguística em que a realização da lateral palatal tende a ser vocalizada [y], ele repetirá este comportamento na escrita, com o grafema “i”?

Para tentar responder a estas questões, investigamos a realização do dígrafo "lh" e seu correlato fônico considerando a representação a partir do repertório linguístico do falante (representação mental), em duas modalidades de registro: a oral e a escrita. Com isto, podemos observar se há um repertório de representações da oralidade e um repertório de representações da escrita e qual o papel da escola no processo de organização do 
sistema linguístico dos falantes. Na seção a seguir, são explicitados os procedimentos metodológicos adotados para a investigação.

\section{Metodologia}

A instituição escolhida para a realização da investigação foi a Escola Estadual Professora Izabel Esteves de Freitas, localizada na região central do Município de Itabaiana/SE. Esta escola recebe alunos da educação infantil ao último ano do ensino médio, provenientes da região central da cidade e também alguns alunos de povoados, especialmente os alunos do ensino médio. O Índice de Desenvolvimento da Educação Básica (IDEB) da escola para os primeiros anos do ensino fundamental é de 4,0 (2007), com projeção de 4,4 para o ano de 2009. A escola apresenta, portanto, um índice abaixo da média nacional, que é de 4,3 em 2007, mas muito superior à média do Estado de Sergipe $(3,4)$ e do Município de Itabaiana $(3,0)$. (BRASIL, 2008).

O protocolo de coleta de dados foi dividido em duas etapas. ${ }^{2}$ Na primeira etapa, os alunos foram convidados a realizar uma atividade conhecida entre os professores das séries iniciais como "ditado mudo" ou "ditado visual", em que o aluno recebe uma folha com figuras e deve escrever os seus respectivos nomes, como pode ser visto na figura 2 .
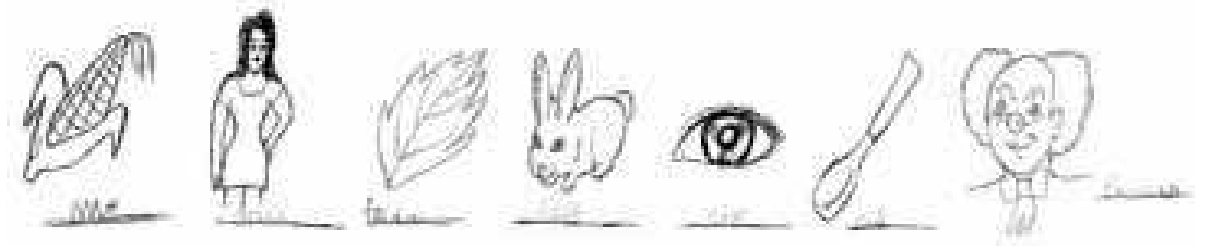

Figura 2: Ditado visual aplicado aos alunos da Escola Estadual Professora Izabel Esteves de Freitas

Os itens lexicais que foram escolhidos para a aplicação do instrumento de coleta foram "milho", "mulher", "folha", "coelho", "olho", "colher" e "palhaço". O critério
2 A coleta de dados foi realizada pelas estudantes Cristiane Oliveira de Jesus, Gilvânia Fontes Lima, e Katiana de Souza Santos, por conta da disciplina Fundamentos Linguísticos para a Alfabetização, no semestre 2009.1. 
3 O coordenador pedagógico da Escola Estadual Professora Izabel Esteves de Freitas não autorizou a coleta de dados em alunos da 1a série, por julgar que estes, que seguem a metodologia do pacote educacional do Programa Alfa\&Beto, poderiam ter conflitos de conteúdo. para a definição destes itens lexicais foi a familiaridade do aluno e também a possibilidade de representação gráfica com a menor possibilidade de ambiguidade.

Após a coleta de dados escritos, os alunos foram, individualmente, convidados a identificar oralmente as figuras, em folha diferente da que fora usada para a coleta escrita. Assim, obtivemos dados orais e dados escritos de itens lexicais em que deveriam, de acordo com a norma culta da língua portuguesa, ocorrer o fonema $/ K /$ e o grafema "lh". Note-se que as possibilidades de realização oral poderiam ser $[K],[1]$, [y] e ainda o cancelamento; na escrita, as possibilidades de realização poderiam ser os grafemas "lh", "l”, "i” e a ausência. Para efeitos de análise, entretanto, optou-se pela oposição marcado socialmente (com as formas [y], [1] e "i" e "l") vs. não marcado socialmente (com as formas $[K]$ e "lh"), explicitada na seção 1 .

Os instrumentos de coleta foram aplicados em 55 alunos, distribuídos entre as turmas da 2a $3^{a}$ a e $4^{\mathrm{a}}$ séries do ensino fundamental. ${ }^{3}$ Após coletados, os dados orais foram transcritos e procedeu-se à categorização, em função dos fatores variante padrão vs. não padrão, item lexical, realização oral vs. escrita, série e sexo. Os dados categorizados foram submetidos à análise estatística do programa GoldVarb X. (SANKOFF; TAGLIAMONTE; SMITH, 2005). 
Tabela 1: Resultados estatísticos para a realização da lateral palatal em dados orais e escritos (valor de aplicação: forma não marcada socialmente)

\begin{tabular}{cccc}
\hline \hline & aplicação/total & percentual & peso relativo \\
item lexical & & & \\
\hline "milho" & $105 / 110$ & $95,5 \%$ & 0,68 \\
"mulher" & $103 / 110$ & $93,6 \%$ & 0,59 \\
"folha" & $94 / 110$ & $85,5 \%$ & 0,35 \\
"coelho" & $104 / 1084$ & $96,3 \%$ & 0,72 \\
"olho" & $101 / 108$ & $93,5 \%$ & 0,59 \\
"colher" & $94 / 109$ & $86,2 \%$ & 0,37 \\
"palhaço" & $83 / 110$ & $75,5 \%$ & 0,20
\end{tabular}

\begin{tabular}{cccc} 
realização & & & \\
\hline escrita & $347 / 380$ & $91,3 \%$ & $*$ \\
falada & $337 / 385$ & $87,5 \%$ & $*$
\end{tabular}

\begin{tabular}{cccc} 
série & & & \\
\hline $2^{\mathrm{a}}$ & $219 / 279$ & $78,5 \%$ & 0,23 \\
$3^{\mathrm{a}}$ & $174 / 182$ & $95,6 \%$ & 0,66 \\
$4^{\mathrm{a}}$ & $291 / 304$ & $95,7 \%$ & 0,66 \\
& & & \\
sexo & & & \\
\hline masculino & $270 / 318$ & $84,9 \%$ & 0,42 \\
feminino & $414 / 447$ & $92,6 \%$ & 0,55 \\
& & & $*$ \\
Total & $684 / 765$ & $89,4 \%$ & sig.: 0,061 \\
\hline \hline
\end{tabular}

Os resultados obtidos estão sumarizados na tabela 1. Retomaremos, na seção a seguir, os resultados relativos a cada fator controlado, para discuti-los à luz dos princípios teóricos evocados.
4 Nos itens "coelho", "olho" e "colher", houve casos em que a criança não nomeou a imagem de acordo com o que era previsto, motivo pelo qual os dados foram descartados, por não conterem a variável sob análise. 


\section{Variante marcada vs. não marcada e a escola}

Retomemos a questão das variantes marcadas socialmente vs. não marcadas. O princípio da marcação fora estabelecido no Círculo Linguístico de Praga para a fonologia. É, pois, altamente focado na questão estrutural, na medida em que se caracterizava oposição binária [+/-], que representa presença ou ausência de um traço fonêmico, passando posteriormente a ser associado à naturalidade e à universalidade. Nesta concepção, um som é dito "marcado" se possui um determinado traço distintivo, como, por exemplo, [nasalidade], em contraponto a outro som em que o traço é barrado. (CRYSTAL, 2003, p. 283-284). Na Sociolinguística, "marcadores" são traços linguísticos social e estilisticamente estratificados, que produzem respostas regulares em testes de reação subjetiva, os quais são contrapostos aos "indicadores" (traços socialmente estratificados, mas não sujeitos à variação estilística, com pouca força avaliativa) e aos estereótipos. (LABOV, 2008). Os dois primeiros são decorrentes de julgamentos sociais inconscientes. Já os estereótipos são formas linguísticas fortemente estigmatizadas, de grande impacto social. Assim, estendendo a noção de marcação para o plano social, podemos estabelecer num contínuo de avaliação social, do mais ao menos marcado socialmente: estereótipo > marcador > indicadores. Nesta escala, a realização fônica de iode [y] para o fonema lateral palatal $/ K /$ pode ser considerada entre o marcador e o estereótipo, daí ser classificada por Brandão (2007) como marcado socialmente; o mesmo podemos dizer para a realização grafêmica ("lh" como não marcado socialmente; "i" marcado socialmente). Espera-se que a escola aja sobre as formas marcadas socialmente, na medida em que é neste ambiente que o falante, em muitos casos, especialmente em comunidades rururbanas e rurais, toma contato com a variedade culta da língua. (BORTONI-RICARDO, 2004).

Nos resultados totais, já apresentados na tabela 1, das 765 ocorrências do ambiente sob análise, 684 ocorrências, correspondendo a $89,4 \%$ dos dados, se referem 
à aplicação da regra, ou seja, ocorrência daquilo que se considera não marcado socialmente, um resultado que contrasta com o apresentado a título de exemplificação do fenômeno, na figura 1, em que o percentual de aplicação da regra é de $72 \%$. A diferença é que os dados que aparecem na figura 1 foram retirados do Atlas Linguístico de Sergipe II (CARDOSO, 2005), que segue a metodologia dos estudos dialetais: referem-se à fala de informantes não alfabetizados ou semialfabetizados provenientes da região rural. Vejamos, então, a questão da oposição entre fala e escrita e o papel da escolarização.

Embora se diga que fala e escrita apresentam diferenças, nos dados analisados a diferença em termos de frequência é minimizada. A realização falada nos dados analisados, de fato, apresenta leve diferença em favor da realização escrita, embora a variável realização não tenha sido considerada estatisticamente significativa (cf. tabela 1). O gráfico da figura 3 , que retoma os percentuais da tabela 1, possibilita visualizar a diferença sutil entre as duas formas de realização.

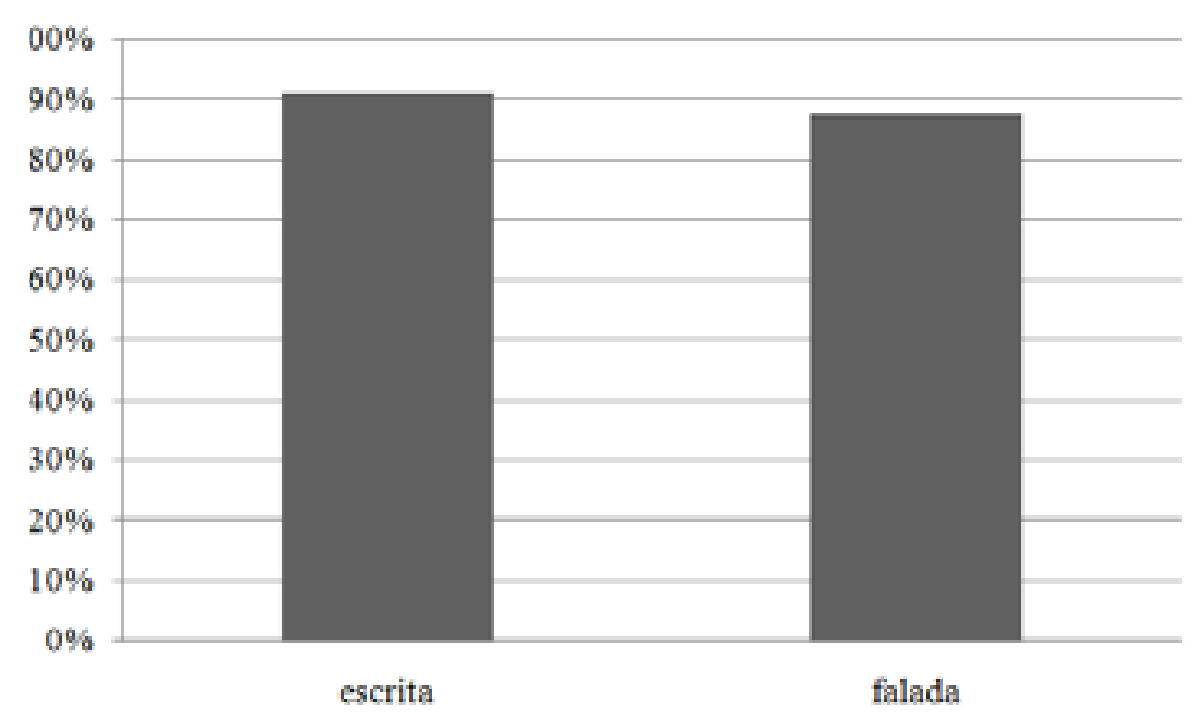

Figura 3: Distribuição da forma não marcada socialmente em função do tipo de realização

Tal resultado sugere que, no modelo analítico construído, a motivação para a variação nas formas da lateral palatal e sua realização grafêmica está relacionada 
com a escola. A escola poderia dinamizar ou refrear a mudança linguística? Votre (2004, p. 51-54) enumera quatro aspectos da escolarização que podem ser verificados na dinâmica social em que a escola interage e que podem estar associados à variação e mudança linguística: i) formas de prestígio e formas relativamente neutras; ii) fenômeno socialmente estigmatizado e fenômeno imune à estigmatização; iii) fenômenos objeto do ensino escolar e fenômenos que escapamà atenção normativa;iv) fenômeno discursivo (ou no mais alto nível gramatical) ou fenômeno da gramática (níveis gramaticais intermediários entre o fonológico e o discursivo). O fenômeno da realização da lateral palatal e seu correspondente grafêmico enquadrase nos três primeiros casos. Vejamos mais atentamente a influência da escola sob o fenômeno.

A figura 4 apresenta o padrão distribucional da aplicação da regra (pesos relativos retirados da tabela 1) em função da escolarização: observe-se que há uma polarização bastante evidente do comportamento da $2 \underline{a}$ série - restringindo a aplicação da norma, com peso relativo de 0,23 - e das demais séries, em que o comportamento em favor da aplicação da regra se mantém estável (peso relativo de 0,66 ).

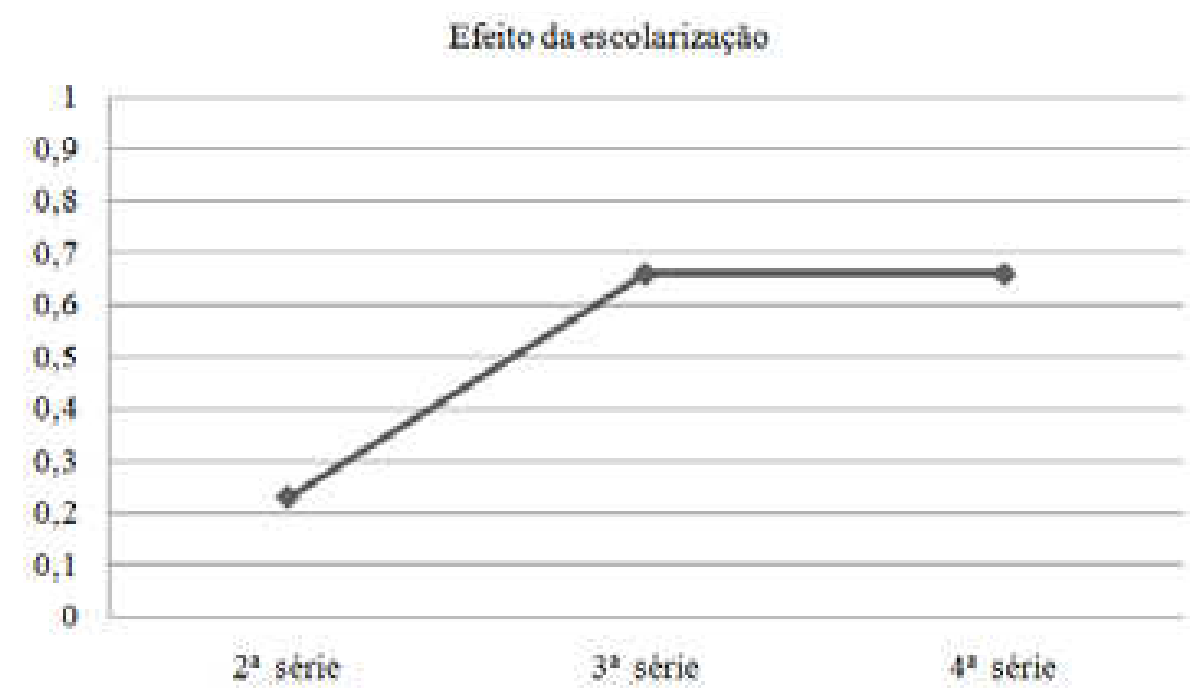

Figura 4: Distribuição da forma não marcada socialmente em função da escolarização 
Se o papel da escola é ensinar a variedade culta, pode-se dizer, com base na análise deste fenômeno, que a escola vem cumprindo o seu papel (Não sabemos a que preço. A escola "corrige" a criança, eliminando a forma errada? Ou a escola apresenta uma nova forma, para ser usada em outro contexto? São questões que saem do escopo desta análise, mas que merecem atenção).

Podemos também buscar uma explicação ontogênica para o efeito da escolarização. No processo de aquisição, a lateral palatal $/ K /$ é tardia e linear. Diz Brandão (2007):

Ressalte-se que variantes aqui consideradas socialmente marcadas se observam nas etapas iniciais de aquisição da lateral palatal. Como demonstrou Hernandorena (1997), quando não se verifica o apagamento, a criança concretiza-a, em qualquer contexto, inicialmente, como [1] (até os 2:4 ou 2:5 anos) e, em seguida, como [y] (até 2:8, 2:9 anos). Só por volta dos 3:6-3:7 anos, começa a implementar [1] , que, como se observa nos corpora aqui focalizados, concorre, em qualquer dialeto, com a variante $[K]$. (BRANDÃO, 2007, p. 97)

As crianças que subsidiaram esta investigação têm entre 8 e 12 anos de idade; nesta idade, a janela da aquisição começa a se fechar. Ao mesmo tempo, é nesta fase que a alfabetização se consolida. O comportamento do grafema "lh" poderia, por hipótese, repetir o que ocorre com a emergência da lateral palatal na aquisição da linguagem. Vejamos o quadro 1, extraído de Cruz (2009, p. 53). 
Quadro 1: Estágios do processo de aquisição das líquidas laterais palatais. Fonte: (CRUZ, 2009, p. 53)

\begin{tabular}{|l|l|l|}
\hline Estágio 1 & Substituição entre líquidas [1] & Ex: “coelho” $\rightarrow$ [cuelu] \\
\hline Estágio 2 & Semivocalização $[\mathrm{y}]$ & Ex: “coelho” $\rightarrow[$ cueyu $]$ \\
\hline Estágio 3 & Produção correta $[K]$ & Ex: “coelho” $\rightarrow[$ cueKu] \\
\hline
\end{tabular}

A criança em fase de alfabetização poderia repetir os estágios da aquisição: "coelo" $\rightarrow$ "coeio" $\rightarrow$ "coelho", embora nestes casos seja mais plausível supor que o "l" ocorra antes do "i”, não por questões ontogênicas, mas conteudísticas e normativas, como o estudo dos dígrafos.

A questão da atribuição de valoração às variantes como marcadas ou não marcadas socialmente é ratificada pelos resultados obtidos em função da variável sexo. As meninas tendem à aplicação da regra, ao uso das formas não marcadas socialmente, ao passo que os meninos tendem à não aplicação, ao uso das formas marcadas socialmente.

Os estudos sociolinguísticos têm constatado a preferência das mulheres por variantes linguísticas mais prestigiadas socialmente, como o são $[K]$ e "lh". As mulheres são, por assim dizer, mais sensíveis ao prestígio social das formas linguísticas, por isso tendem a liderar processos de mudança linguística que envolvem variantes prestigiadas. Quando as variantes são socialmente desprestigiadas, as mulheres assumem uma atitude conservadora (neste caso, homens tendem a liderar a mudança). Obviamente, as explicações para as diferenças linguísticas entre homens e mulheres devem ser relativizadas em função do grupo social considerado. No espaço escolar, onde foi realizada a investigação da realização da lateral palatal e seu correspondente grafêmico, os resultados obtidos corroboram a preferência das mulheres pelas variantes não marcadas socialmente, como podemos observar na figura 5. 
Figura 5: Distribuição da forma não marcada socialmente em função do sexo dos informantes

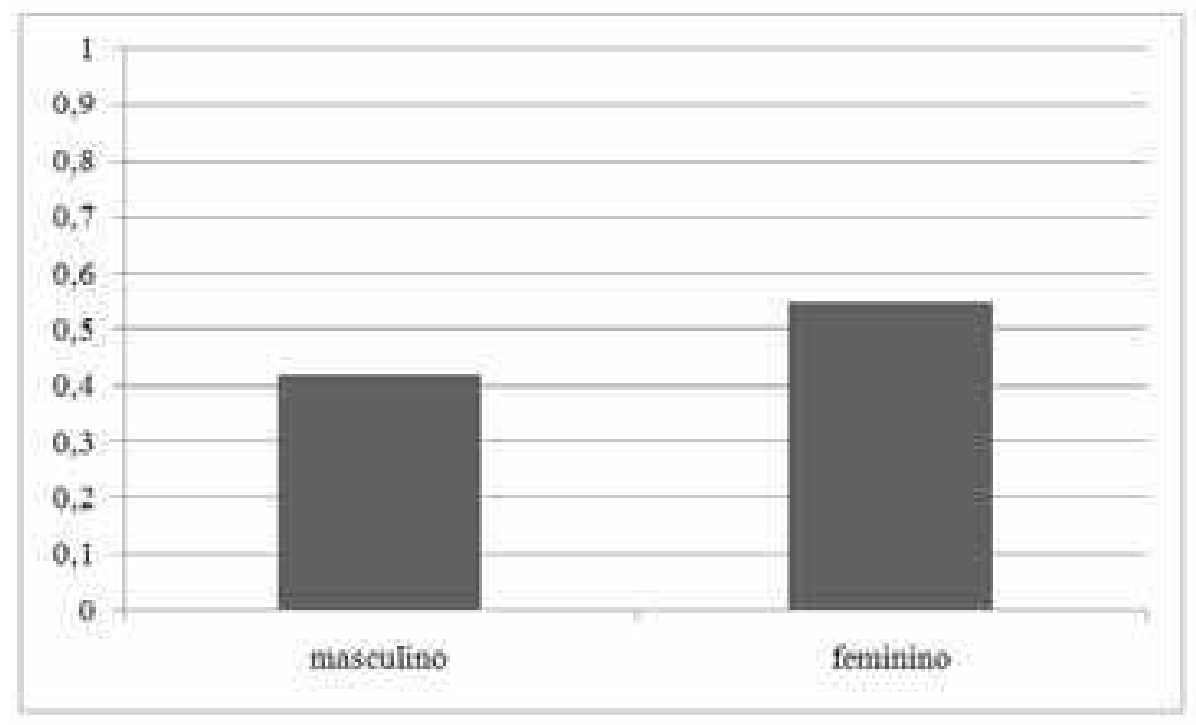

Em suma, estes resultados confirmam o valor social das formas aventado por Brandão (2007) (o comportamento linguístico das meninas ratifica uma variável não marcada socialmente) e ressaltam o papel da escola na deriva das formas variantes. Ao contrário do que se poderia supor, o tipo de registro mostrou-se pouco influente na escolha das formas. Vejamos, na seção a seguir, o efeito da frequência e da recorrência de itens na representação do sistema linguístico dos indivíduos analisados.

\section{Coleção de itens e frequência de uso}

Para esta análise, assumimos a perspectiva da fonologia de usos, postulada por Bybee (2001). Vimos na seção anterior os efeitos dos usos sociais e interacionais no fenômeno sob análise. Passemos agora para os efeitos do uso sobre o processamento da língua. Vimos que palavras e sintagmas de alta frequência têm representações mais fortes (são mais facilmente acessadas e menos propícias a sofrerem mudança por analogia), enquanto palavras e sintagmas de baixa frequência são mais difíceis de serem acessadas e tornam-se mais difíceis de serem lembradas (e, portanto, mais suscetíveis à mudança). 
Vejamos na figura 6 a distribuição das ocorrências em função do item lexical (sempre tendo como valor de aplicação as formas não marcadas socialmente). Podemos estabelecer uma escala dos itens lexicais em função da aplicação da regra: os itens que mais favoreceram a aplicação da regra foram "milho" e "coelho", com pesos relativos na casa de 0,70. Em seguida, vêm os itens "mulher" e "olho", com peso relativo na casa de 0,60. Estes são os itens lexicais que mais favoreceram as formas não marcadas socialmente. Na outra ponta da escala, estão os itens "folha" e "colher", com peso relativo na casa de 0,35 , e o item "palhaço", com peso relativo de 0,20 , fortemente restringindo a ocorrência das formas não marcadas socialmente.

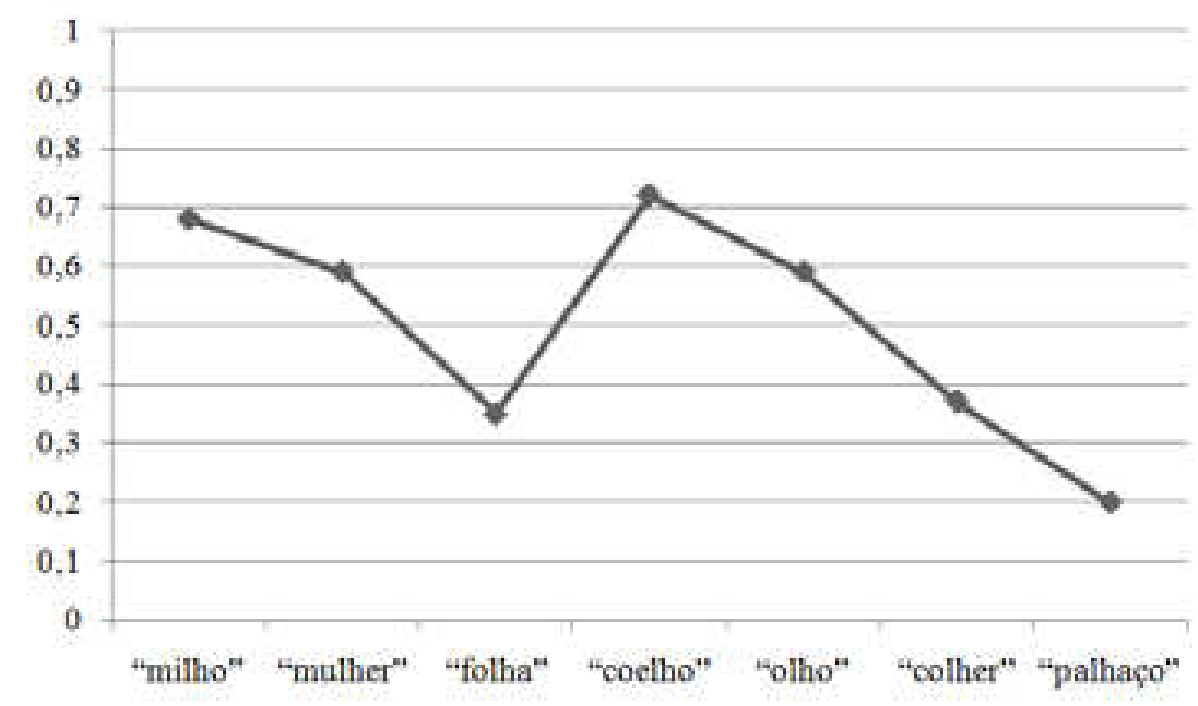

Figura 6: Distribuição da forma não marcada socialmente em função dos itens lexicais

Vale dizer que a escolha dos itens lexicais para o instrumento foi pautada no critério figurativo (deveria ser de fácil reprodução e a criança deveria identificar sem ambiguidade a representação gráfica). Possivelmente, "palhaço" é um item lexical pouco recorrente, seja na interação, seja no conteúdo escolar; já "milho" e "coelho" são certamente mais recorrentes, especialmente pelo perfil da cidade de Itabaiana/SE, um entreposto comercial, celeiro do Estado. 
É interessante notar que o item "mulher" apresenta tendência à aplicação da regra de uso de variante não marcada socialmente: "fia" e "muié" são vocativos frequentes na fala da região. Talvez por isso, este item seja alvo de conteúdo escolar, com treino para o uso da forma de prestígio, da forma não marcada socialmente. Como defende Bybee (2001), os falantes organizam o conteúdo gramatical da língua baseado em lexias, correlacionando fortemente a forma e o significado. Assim, a recorrência de um traço em um item lexical vs. a restrição desta recorrência em outro item lexical é resultado da exposição ao input, à frequência de uso.

As representações linguísticas de um falante, ou de um grupo de falante, têm natureza múltipla e estão em competição [...]. Os falantes apresentam várias representações em competição entre si e entre as representações da comunidade de fala. As representações múltiplas são gerenciadas probabilisticamente e determinam tendências gerais. (CRISTÓFARO-SILVA, 2006, p. 36-37)

Considerando o papel da escola de ensinar a variedade culta da língua, e que $[K]$ e "lh" são as formas prestigiadas, o conteúdo escolar deve contemplar a natureza probabilística do fenômeno, ampliando a exposição do aluno a itens lexicais diferentes, a fim de que a regra se generalize.

\section{Considerações finais}

Estudos de interface sociolinguística que contribuam para o ensino de língua materna são sempre bem vindos para delinear o palco escolar brasileiro, heterogêneo e contrastante por natureza. Neste texto, abordamos uma realização linguística que é socialmente marcada, as variantes da lateral palatal e seus correspondentes grafêmicos. $\mathrm{O}$ estudo investigativo empreendido constatou que as regras de representação 
grafofonêmicas para o dígrafo "lh" são moldadas pela escola; apesar da forte atuação do input, a regra de conversão e desconversão do dígrafo "lh" privilegia a forma não marcada socialmente. A representação mental da lateral palatal e de suas formas variantes (e os equivalentes grafêmicos) é modelada pelo uso, especialmente pela frequência de ocorrência de dadas lexias: o uso modela a língua.

Em suma, com este estudo, evidenciamos a correlação entre o repertório de representações da oralidade e o repertório de representações da escrita, correlação esta que é mediada pela escola. 


\section{Referências}

BORTONI-RICARDO, Stella Maris. Educação em língua materna: a sociolinguística na sala de aula. São Paulo:

Parábola, 2004.

BRANDÃO, Silvia Figueiredo. Um estudo variacionista sobre a lateral palatal. Letras de Hoje. Porto Alegre, v. 42, n. 3, p. 89-99, setembro 2007.

BRASIL. Ministério da Educação. Instituto de Pesquisas Educacionais Anísio Teixeira. Relatório do Índice de Desenvolvimento da Educação Básica (IDEB). Brasília, 2008.

BYBEE, Joan. Phonology and language use. Cambridge: Cambridge University Press, 2001.

CAMARA Jr., Joaquim Mattoso. Estrutura da língua portuguesa. Petrópolis: Vozes, 1972.

CARDOSO, Suzana Alice Marcelino. Atlas Linguístico de Sergipe II. Salvador: EDUFBA, 2005.

CRISTÓFARO-SILVA, Thaïs. Fonética e fonologia do português. 4. ed. São Paulo: Contexto, 2000.

CRISTÓFARO-SILVA, Thaïs. Fonética e fonologia: perspectivas complementares. Revista de Estudos da Linguagem. Vitória da Conquista, v. 3, n. 3, p. 25-40, julho 2006.

CRUZ, Gabriela Fontana Abs da. O processo de semivocalização de líquidas laterais em posição pré-vocálica: uma revisão teórica. Letrônica. Porto Alegre, v. 2 , n. 2 , p. 4858, dezembro 2009. 
CRYSTAL, David. A dictionary of linguistics and phonetics. 5. ed. Oxford: Blackwell, 2003.

LABOV, William. Padrões sociolinguísticos [trad. Marcos Bagno, Marta Scherre e Caroline Oliveira]. São Paulo: Parábola, 2008.

LABOV, William. Principles of linguistic change: internal factors. Oxford: Blackwell, 1994.

SANKOFF, David, TAGLIAMONTE, Sali, SMITH, Eric.

Goldvarb $X$ : A variable rule application for Macintosh and Windows. Department of Linguistics of University of Toronto, Department of Mathematics of University of Ottawa, 2005.

VOTRE, Sebastião Josué. Relevância da variável escolaridade. In: MOLLICA, Maria Cecília; BRAGA, Maria Luiza (orgs.). Introdução à sociolinguística: o tratamento da variação. São Paulo: Contexto, 2004, p.51-57. 